\title{
TEACHING AIRCRAFT DESIGN THROUGH A BLENDED LEARNING METHOD IN A HIGHER EDUCATION
}

\author{
Agnieszka Kwiek $^{1}$ \\ ${ }^{1}$ School of Computing Engineering and Mathematics \\ University of Brighton \\ Cockcroft Building, Lewes Rd, BN2 4GJ, Brighton, UK \\ A.Kwiek@brighton.ac.uk
}

Keywords: Aircraft design education, blended learning, Nearpod, higher education

\begin{abstract}
A blended learning is a method which combines a few teaching methods. Usually it is a mix of classic teaching approach with using of online tools. A Nearpod is technology enhanced learning (TEL) tool which allows for creating an interactive presentation which can be delivered in a real time session or in a self-paced mode. The presentation can be displayed on a student's computer or mobile phone. This paper presents how students experience can be enhanced by the implementation of a blended learning in aircraft design lectures. And how a Nearpod can be integrated into those lectures to help students develop such skills as creativity, critical thinking and problem solving, which are vital for aircraft design project and students' further career in the aerospace sector. This study focuses on aeronautical students studying at the University of Brighton in School of Computing Engineering and Mathematics. Students group includes BEng., MEng. and BSc. Top-Up students who were enrolled in level 6 module - ME351 Aircraft Design and Management Project. Results reveal that students' attendance is higher than traditional lectures and the most favorite and helpful activities are quizzes \& polls, draw it and fill blanks. Aerospace engineering students prefer Nearpod activities where they can choose an answer or draw it rather than writing it.
\end{abstract}

\section{INTRODUCTION}

At a traditional university, a typical aircraft design module includes lectures or group project or a combination of both [1], [2]. Students can be mark based on the project [2], [3] or an exam and project [4]. In case of undergraduate course, students' projects usual focuses on a conceptual design [2], [5], [6], [7]. A master module might also cover a preliminary and detailed design [3]. Designing requires decisions making, sometimes with a limited knowledge, it's challenging for students because usually most of the modules require more analytical skills rather than creative thinking skills [2], [3]. In case of design, the same problem can be solved in different ways which might depends on such factors as customer preferences, market demands, access to specific technology, certification specifications or it could be the implication of previous decisions. There is no one answer (solution) for the design but there is an area of possible solutions and the role of the designer is making decisions, which students usually struggle with. Students' experience can be also improved by integration of computer aided design tools [2] as well as flight simulator [1]. However, students have to learn how to express critical conclusions and demonstrate an engineering common sense, which is challenging because most of the students usually believe unconditional with results obtained by computer [2]. Moreover, such skills as creativity and problem solving are critical in terms of students' employability in the aerospace industry [8]. 
This paper presents how students experience can be enhanced by the implementation of a blended learning in aircraft design lectures. And how a Nearpod can be integrated into those lectures to help students develop such skills as creativity, critical thinking and problem solving, which are vital for aircraft design project and students' further career in the aerospace sector.

\subsection{Blended learning}

According to a literature review in the traditional lecture, a student does not use many skills, on the other hand, the pure self-paced method does not work either [1]. An unconventional teaching method for aircraft design high education was also investigated, for example lectures delivery via virtual words [4]. Students were watched lectures livestream and communicate with class mates and teacher trough a virtual world. This study shows that $2 \%$ difference was noticed between exam marks of students who attended the classic lectures and via virtual worlds. According to [1] the best solution is a mixed method which combines traditional lecture, interactive tools, self-paced tutorials and field trip. A blended learning [9] is a method which combines a few teaching methods. Usually is a mix of classic teaching approach with using of online tools. This kind of method could be a good solution for a problem of an increasing class size, and a diverse group level as well as can improving students' experience.

\subsection{Nearpod}

A Nearpod [10] is an enhanced learning tool which allows for creating an interactive presentation with quizzes, polls, drawing activities, fill blanks, memory test, and collaboration board. Moreover, the presentation can include videos, field trip, PhET simulation and 360 degrees pictures. The presentation can be displayed on a student's computer or mobile phone. And it can be delivered in a real time instructor lead mode or in a self-paced mode. In case of instructor lead mode, a slide change automatically on students' devices, when the slide was changed on instructor's device. A teacher can track students' progress in a real time and all students' progress can be shared with the class. A student can access a presentation in the app or directly in the Internet web browser. For each presentation, a unique code is generated, and by entering this code into window student can join to a session.

\subsection{Blackboard Learn}

A Blackboard Learn [11] is a virtual learning environment which allows to manage a course content and creating online tests and submission points. It could be used as well for formatives tests and assignments. Each student has an individual account and access to a module area. A module instructor can access students' submissions and track students' progress via grade centre. Moreover, through the Blackboard Learn students can have access to a discussion board, where they can communicate with an instructor or each other. At the University of Brighton all modules content is managed by Blackboard Learn.

\section{AIRCRAFT DESIGN EDUCATION}

This paper focuses on aeronautical students studying at the University of Brighton in the School of Computing, Engineering and Mathematics. Students' group includes MEng., BEng. and BSc. (Top-Up) students; all students attended together into classes and were enrolled in the same module - ME351 Aircraft Design and Management Project. This is a level 6 module and is compulsory for all students on an aeronautical engineering course, the class counted 44 students. ME351 module consists of two types of lectures and assignments, the first was aircraft design and the second was project management with elements of innovative product development. This paper focuses only on aircraft design part, the assignment was a group project and each group worked on the conceptual design of a different aircraft, this assignment required teamworking, making decisions, creative thinking, 
problem solving, and critical thinking skills. The Aircraft Design part of ME351 module covered such topics as trend analysis, weight estimation, range-payload diagram, constrain diagram, aircraft sizing, balance calculation, aerodynamic and stability computations, performance, V-n diagram, cost estimation, aircraft loads and conceptual design of aircraft structure.

\section{BLENDED LEARNING IMPLENETATION FOR AIRCRAFT DESIGN LECTURES}

In case of classic lecture and group of 44 students it could be a challenge to provide activities, which help students to improve their intellectual skills; even if students are doing activities in groups, it still is a risk that only a few students actually working, and rest will be only passive participants. The understanding of a problem by a student is increased if the student has an opportunity to engage in activity which required an application of the knowledge, not only listening to a lecture or copy an example solved by a teacher on a blackboard. To improve students' experience all lectures were delivered through Nearpod to ensure an equal access to the Nearpod presentation all lectures session were taught in a computer lab and, each student sited in front of one workstation (number of the computers in the lab was bigger than the number of students enrolled on the module). Most of the presentations were delivered in instructor lead mode. Nerarpod presentations were supported by materials available on Blackboard Learn; students could access lectures slides, Panukl and SDSA tutorials, examples including online formative tests, and other online resources. Moreover, students could use the discussion board to communicate with lectures or each other.

To improve students' problem solving, critical thinking and creativity skills different types of activities were implemented (see Figure 1 and Figure 2). Some activities required decision making, for example how a student would simplify model in case of creating a simple CFD model, how a student would plan to aircraft assembly in case of redesign aircraft in composite technology, how student comments a picture of aircraft with rectangular windows, which aerofoil student would select, how a student would plan to attach an engine to a wing. Another type was trying to guess, e.g. displacement of Airbus A350 wing-tips during the test, how far a general aviation aircraft gliding after the engine failure, a thickness of the aircraft skin (before information about aircraft structure were delivered), a weight of the aircraft paint. Moreover, activities which required engineering calculations such as calculation of design lift coefficients, V-n diagram, fuselage loads or skin thickness. Nearpod was also used for reviewing of students' current knowledge regarding high lift devices, wing geometry, and calculations of shear force and bending moment. Interactive activities were supplemented by online videos, virtual field trip, e.g. e-visiting aerospace museum, and aircraft inside via 360 degrees pictures. Students can also use the Nearpod self-paced mode, for example to understand how to use Corke's excel spreadsheet.
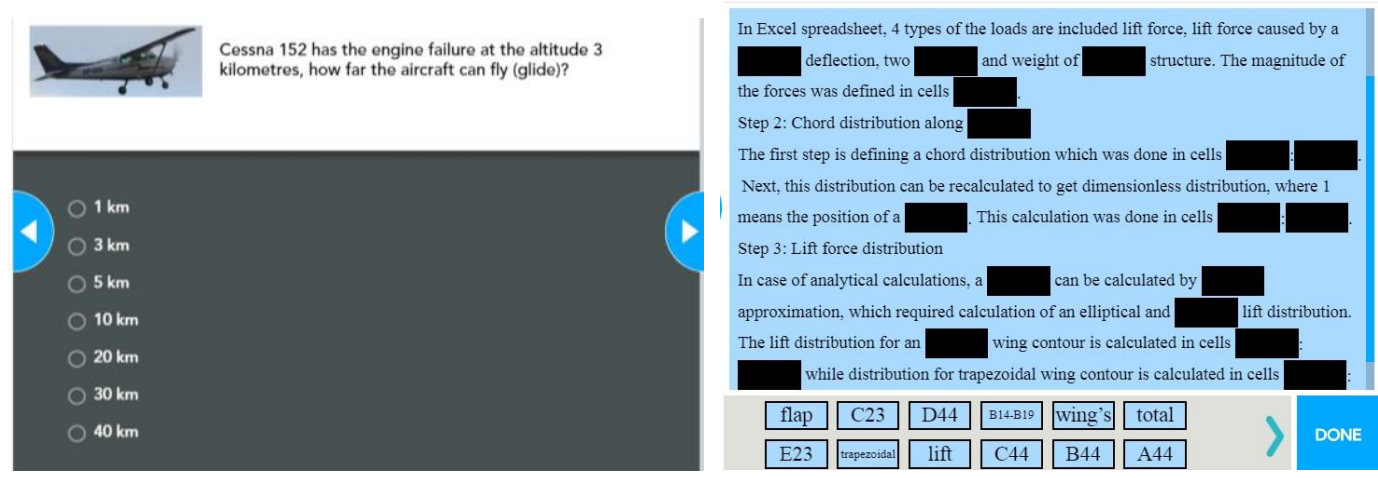

Figure 1 Example of Nearpod poll (on the left) and fill blanks activity (on the right) 

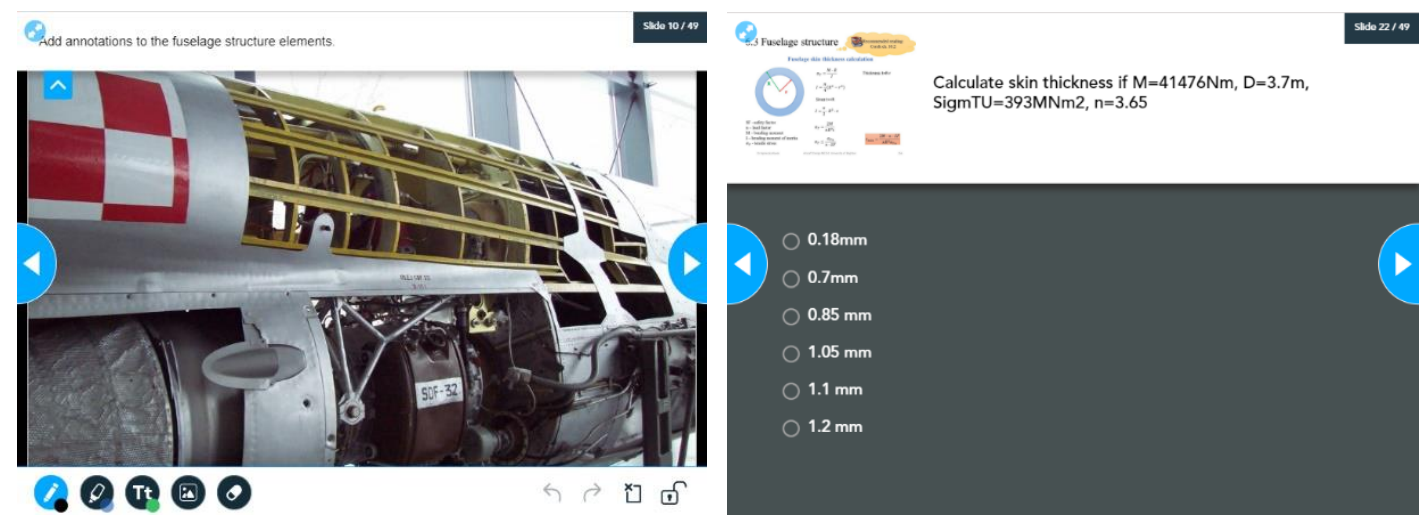

Figure 2 Example of Nearpod draw it activity (on the left) and quiz (on the right)

\section{NEARPOD IMPACT ON STUDENTS' PERFORMANCE AND SKILLS}

To investigate an impact of Nearpod on students' performance and skills a small research project [12] was established as a part of author Post Graduate Certificate LT751 Educational Enquiry module.

\subsection{State of the art}

There is no published paper which presenting research into Nearpod application in aircraft design lectures. However, a study in a case of STEM related subjects was carried out, Nearpod is promoting engagement and improving material understanding tool [13]. Report [14] shows that Nearpod can reducing distractibility of students and help students to learn more and participate more. On the other hand, the positive impact of active learning on STEM students' performance was investigated in [15]. The biggest improvement was noticed for good students, and the students' performance was measured by students' mark. In case of ME351 aircraft design lectures, active learning activities were implemented in session through Nearpod, what should cause improvements of students' marks.

\subsection{Methodology}

The data was collated in two ways. The first data source was Nearpod reports, those 11 reports (one per session) include information about students' attendance and information about students' response for each interactive activity. The second data source was anonymous paper questionnaires [12], [16] which was filled by 13 participants during the last lecture session. The participants included 5 BSc students, 4 BEng students, and 4 MEng students. The questionnaire consisted of 13 questions, including self-assessment questions regarding the impact of Nearpod interactivity activities on student's skills development. To evaluate students' attendance the data was compared with ME352 Avionics lectures, the cohort included the same 44 students. Students' marks were compared with ME337 Aircraft Design projects marks, this module was the old version of ME351 and had been taught through PowerPoint presentation in spring 2017.

\subsection{Results Nearpod}

The first set of data was collected using Nearpod reports which could be accessed after each session. Figure 3 presents students' attendance on aircraft design lecture across the semester, the average attendance was $68 \%$, while for the same group of students the average attendance in case of traditional lectures (ME352) it was 50\%. The maximum and minimum attendance for traditional lectures was $29 \%$ and $76 \%$ respectively. The drop-in attendance at the end of the semester is caused by a higher number of assignments and due to students' earlier travel to home before Christmas. Figure 4 (on left) presents students engagements - the percentage of response provided by students who attended the session (data collected for all 11 lectures); the most favorite activities were polls, 
draw it and quizzes. Figure 4 (on right) shows students' engagement in their favorite activities, the average engagement was $68 \%$. Based on this data can be concluded that aeronautical students prefer activities where they can select the answers or draw it rather than writing the answer in an open question window or collaboration board.

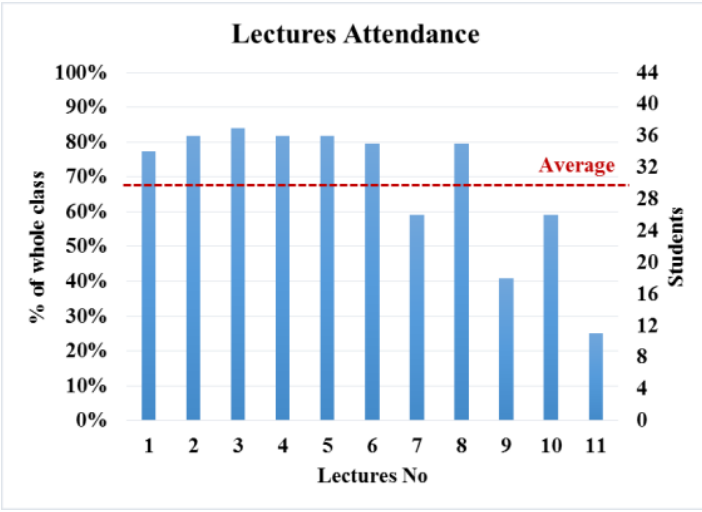

Figure 3 Students' attendance across all lectures.
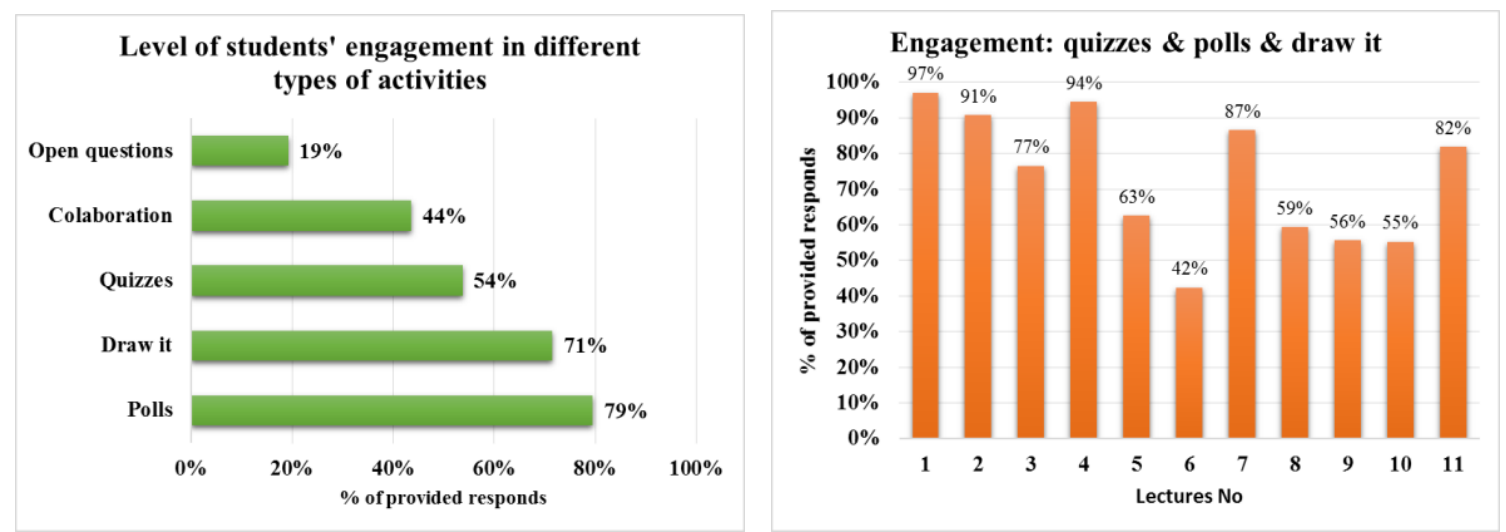

Figure 4 Students average engagement in case of different activates (on the left) and engagement in their favourite activities across all lectures (on the right).

\subsection{Results questionnaire}

The second set of data was collected based on the questionnaire, which included questions regarding preference of lectures delivery method, learning style and impact of Nearpod on student's skills development (student's self-assessment). Figure 5 (on the left) shows the ranking of lectures delivery method, $85 \%$ of students selected Nearpod (instructor lead or self-paced mode) as the best method. Only $15 \%$ of students selected PowerPoint as the best method but as a second choice, they selected Nearpod instructor lead or self-paced mode. Figure 5 (on the right) shows that $85 \%$ of students enjoyed ME351 lectures and $15 \%$ of students had a neutral opinion. 


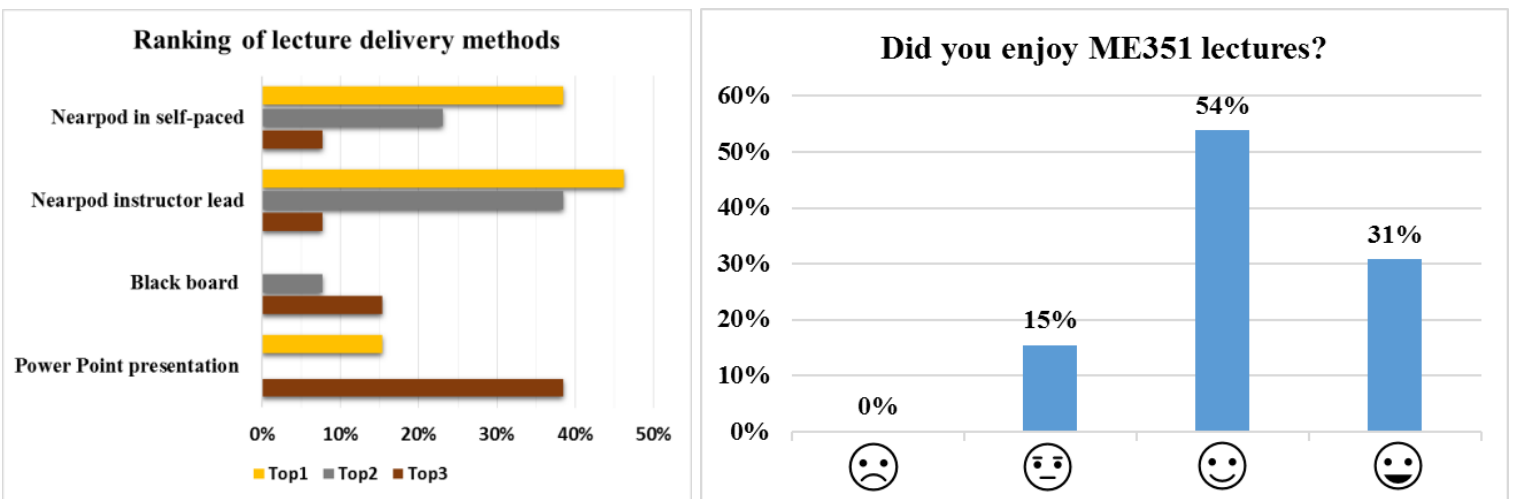

Figure 5 Ranking of lectures delivery method (on the left) and students ranking of ME351 lectures (on the right).

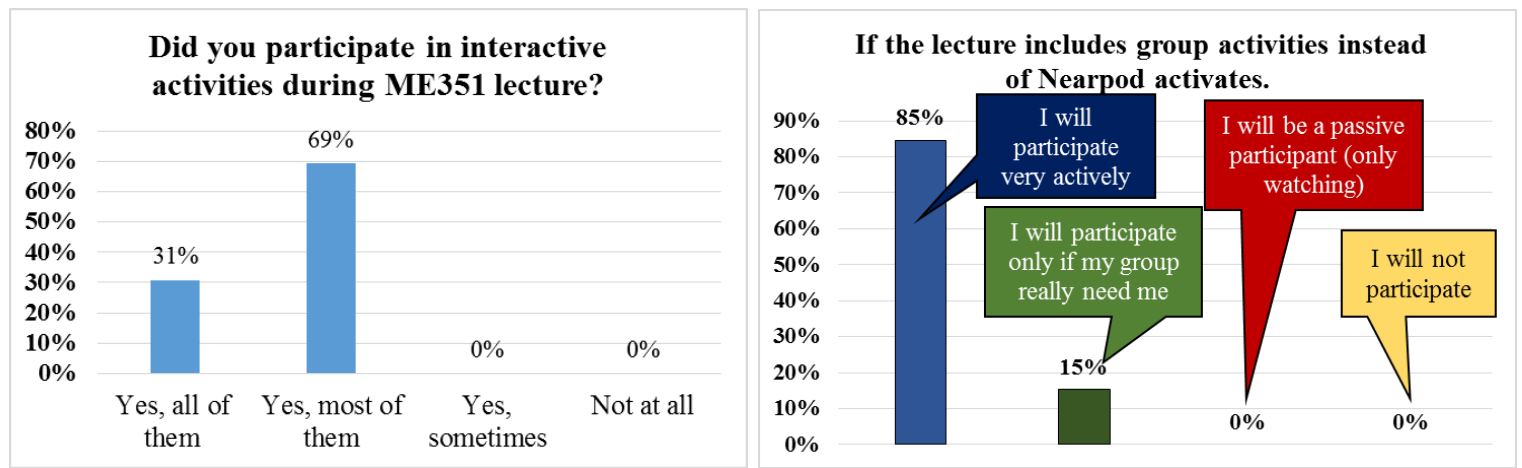

Figure 6 Students self-assessment of participation in Nearpod activities (on the left) and engagement in group activities in case of a classic lecture (on the right).

Figure 6 (on the left) shows that all students were very engage in Nearpod interactive activities, on the other hand $15 \%$ of students said that in case of classic lecture they will be participating in group activities only if they group really need them (Figure 6 on the right), those 15\% selected that they participate in most of the interactive activities.

Figure 7 and Figure 8 show which types of Nearpod activities are the most helpful for students' skills development, the preferences are different and depends on the group (Bsc, BEng or MEng). But in all groups, some of the students identified the negative impact of the collaboration board. According to BEng the highest positive impact on skills development had quizzes, $73 \%$ positive opinions. According to BSc the highest positive impact on skills development had fill blanks and quizzes respectively $100 \%$ and $92 \%$ positive opinions. According to MEng the highest positive impact on skills development had quizzes and draw it, both $92 \%$ positive opinions.

Figure 9 and Figure 10 show which types of Nearpod activities are the most helpful for creativity skills, solving problem and critical thinking skills development. According to students' self-assessment, quizzes had the biggest positive impact on all skills type (creativity skills, solving problem, and critical thinking) development. In case of the critical thinking also fill blanks achieved the same value of positive impact as quizzes. 


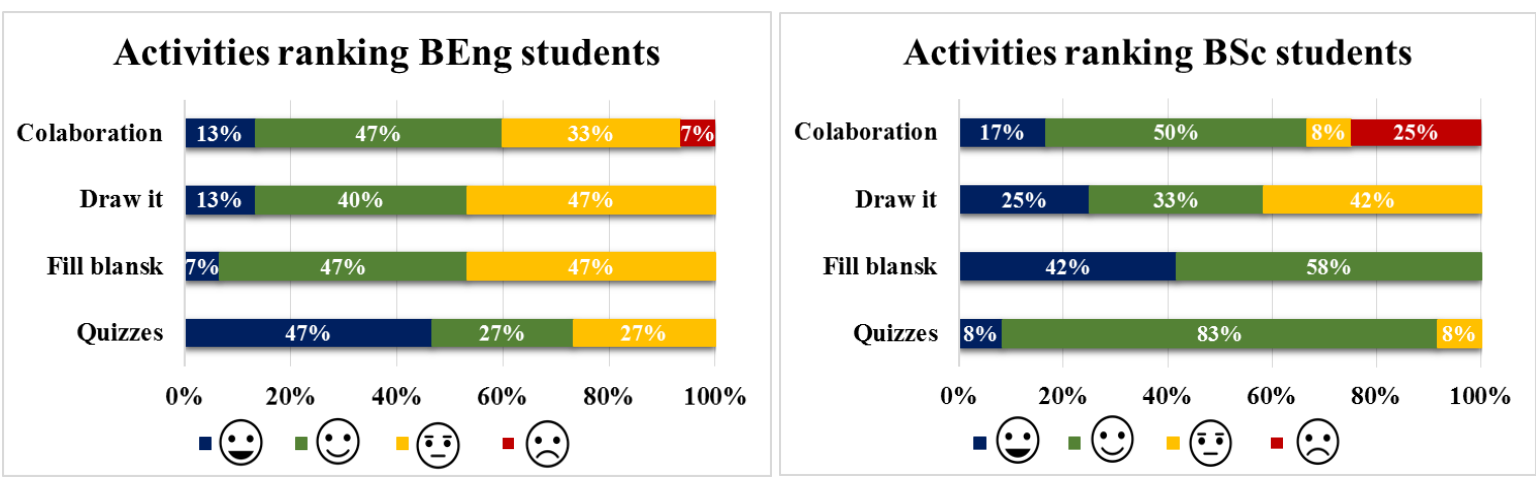

Figure 7 Summary of the activities ranking according to BEng. students (on the left) and BSc. students (on the right).

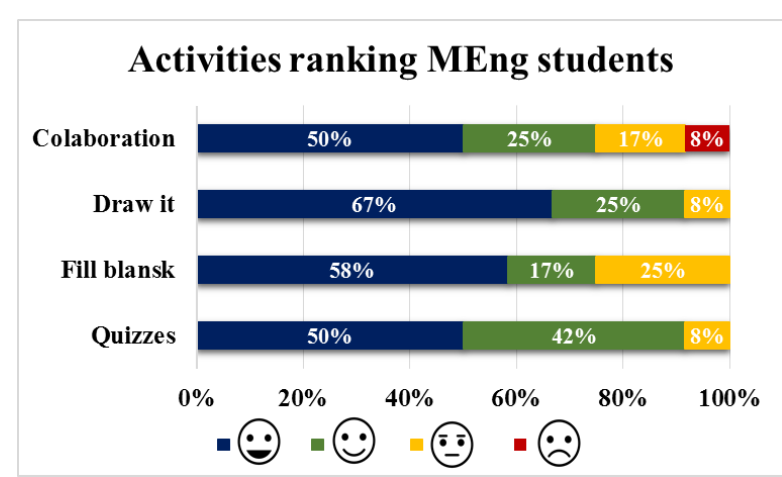

Figure 8 Summary of the activities ranking according to MEng. students.

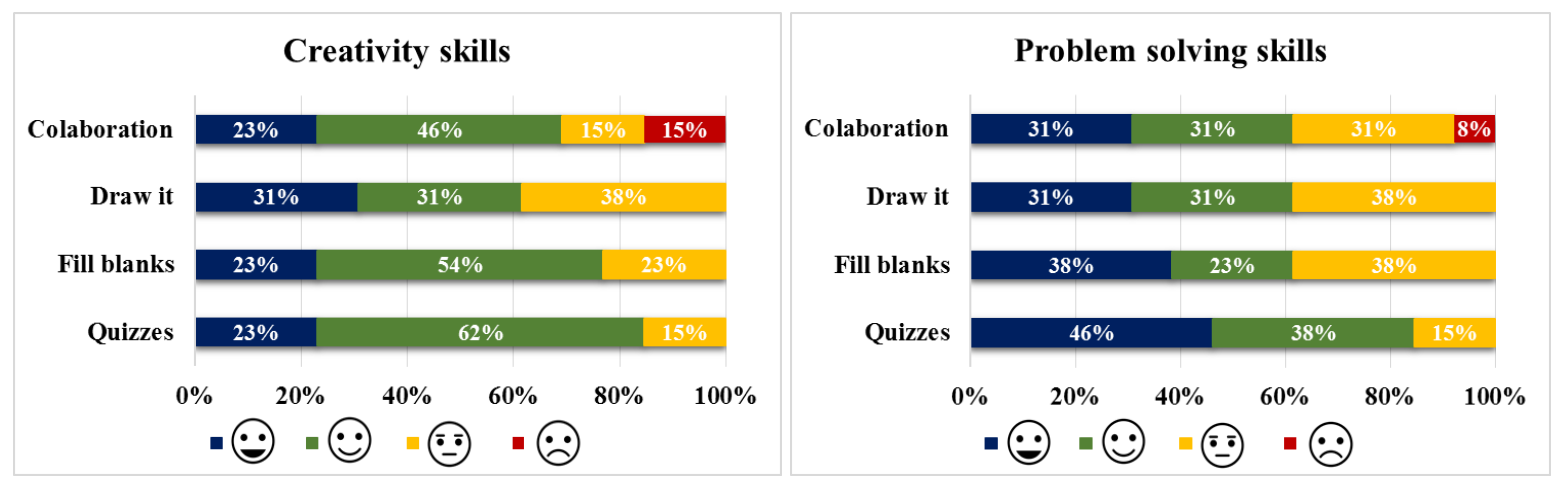

Figure 9 Summary of the activities development ranking in terms of creativity skills (on the left) and problem solving (on the right).

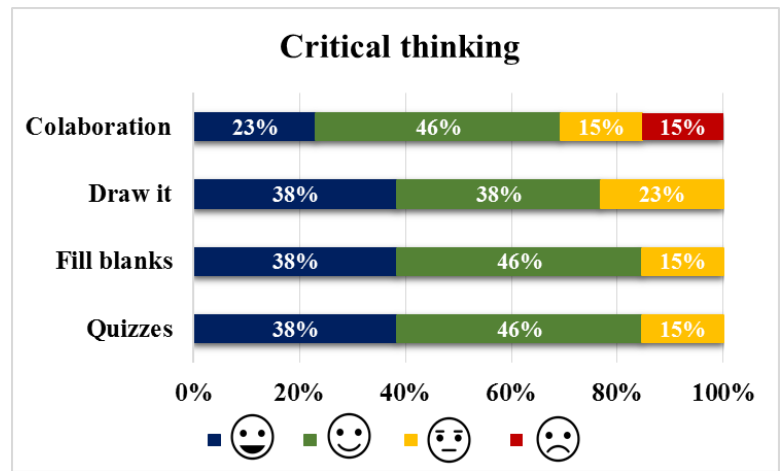

Figure 10 Summary of the activities development ranking in terms of critical thinking. 


\subsection{Marks distribution}

Figure 11 presenting the project mark distribution, on the left for module delivered via PowerPoint and on the right module delivered via Nearpod. Where $40 \%$ is a threshold for a pass mark and $70 \%$ is a threshold for the first class mark. The positive impact of Nearpod implementation on MEng students was noticed, all students got a pass mark and the number of the first class mark increased from $27 \%$ to $50 \%$. Moreover, the range of the first class mark was extended. In case of BSc students, the number of failed dropped and the number of the second class mark (50-69\%) increased. In case of the BEng students, the impact was noticed for good students, more students achieved the first class mark and highest marks were achieved. On the other hand, more BEng students failed the module delivered by Nearpod.
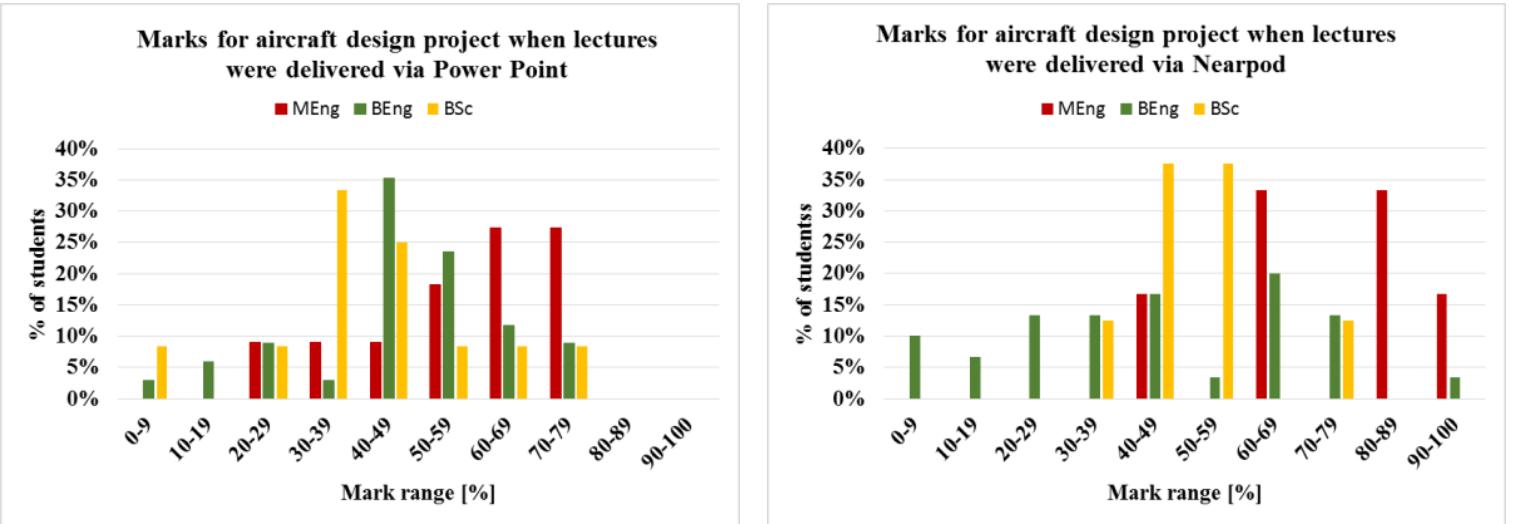

Figure 11 Students' marks distribution in case of lectures delivered via PowerPoint (on the left) and Nearpod (on the right).

\section{CONCLUSIONS}

The aircraft design module has been successful deliver through blended learning technique. Blackboard Learn was used to manage module materials, assignments submission \& feedback and provide formative online tests. The Nearpod was used for lectures delivery, most of the sessions were taught in the instructor lead mode. Students' attendance was higher than for classic lectures, and the average attendance was $18 \%$ higher for Nearpod sessions. Both Nearpod report and student selfassessment confirmed that the most favorite and helpful activities are quizzes \& polls, draw it and fill blanks. Aerospace engineering students prefer Nearpod activities where they can choose an answer or draw it rather than writing it. However, it is important to understand that just implementation of the Nearpod does not guarantee success, the presented content has to be good quality and interactive activities have to arouse curiosity.

Based on the student self-assessment it could be concluded that Nearpod is a useful tool to help develop students' skills. However, it is recommended to carried out more extended research which includes testing students' skills before and after module participation, not only based on student selfassessment. And extend the research methodology on a focus group to better understand how the module delivery can be improved to decrease the number of failed marks in BEng students group. Moreover, this is the first time ME351 module has been delivered, collecting the data across a few years might help improve current study and draw deeper conclusions.

\section{ACKNOWLEDGEMENTS}

The author would like to express her gratitude to Dr John Canning for his advices and support in her LT751 Educational Enquiry project. Moreover, author would like to thank CEM colleagues for their 
support, especially Dr Deshinder Singh Gill for sharing data about ME352 Avionics lectures attendance. The author also would like to thank all the students who filled out the questionnaire.

\section{REFERENCES}

[1] Scholz D., Thorbeck J. (2000). Computer Based Training in Aircraft Design Education. Proceeding of 22nd Congress of International Council of the Aeronautical Sciences, Paper ICAS 2000-1.7.3.

[2] Whitford R. (1996). An Anglo-US view of aircraft design education. Proceeding of 20th Congress of International Council of the Aeronautical Sciences, Paper ICAS-96-3.4.3.

[3] Jouannet C., Berry P. and Krus P. (2007). Aircraft design education at Linköpings University. Proceedings of the Institution of Mechanical Engineers Part G Journal of Aerospace Engineering 221(2), 217-224.

[4] Okutsu M., DeLaurentis D., Brophy S., Lambert J. (2013). Teaching an Aerospace Engineering Design Course via Virtual Worlds: A comparative assessment of learning outcomes. Computers \& Education Journal 60 (1), 288-298.

[5] Cummings R.M., Hall D.W. (2005). Aircraft Design for Second-year Undergraduate Students. International Journal of. Engineering Education 21 (2), 341-349

[6] Young T. M. (2000). Aircraft Design Education at Universities: benefits and difficulties. Aircraft Design 3 (4), 207-215.

[7] Martinez-Val R., Perez E. Teaching Airplane Design: A Multi-Level Approach. (1997). International Journal of. Engineering Education 13 (4), 304-312

[8] Tana S., Marsdenb C. and Zenga Y. (2016). Educating Aerospace Design Engineers:Perspectives from Design Creativity Theory. Proceedings of the Canadian Engineering Education Association (CEEA) Conference- Dalhousie University June 19-22, 2016

[9] Boelens R., Voet M., De Wever B. (2018). The design of blended learning in response to student diversity in higher education: Instructors' views and use of differentiated instruction in blended learning. Computers \& Education Journal Vol. 120, 197-212

[10] https://nearpod.com/ (accessed 25/06/2018)

[11] https://studentcentral.brighton.ac.uk/webapps/login/ (accessed 10/07/2018)

[12] Munn P., Drever E. (2004). Using questionnaires in small-scale research: a beginner's guide. The SCRE Centre.

[13] McClean S. and Crowe W. Utilising Nearpod to promote active learning in lectures, available online: http://uir.ulster.ac.uk/37135/3/Nearpod\%20Report.pdf (accessed 10/07/2018)

[14] https://nearpod.com/page/pdf/research-dakota-web.pdf (accessed 10/07/2018)

[15] Freeman S., Eddy S. L., McDonough M., Smith M.K., Okoroafor N., Jordt H. and Wenderoth M. P. (2014). Active learning increases student performance in science, engineering, and mathematics. Proceedings of the National Academy of Sciences of the United States of America 111 (23), 84108415.

[16] Cohen L., Manion L., Morrison K. (2018). Research methods in education. Eight edition. Abingdon: Routledge. 


\section{COPYRIGHT STATEMENT}

The authors confirm that they, and/or their company or organization, hold copyright on all of the original material included in this paper. The authors also confirm that they have obtained permission, from the copyright holder of any third party material included in this paper, to publish it as part of their paper. The authors confirm that they give permission, or have obtained permission from the copyright holder of this paper, for the publication and distribution of this paper as part of the READ 2018 proceedings.

This is an open access article distributed under the Creative Commons Attribution License which permits unrestricted use, distribution, and reproduction in any medium, provided the original work is properly cited. (CC BY 4.0). 